\title{
A OPERAÇÃO INTERNA DOS TRATADOS INTERNACIONAIS
}

\author{
Juliano Scherner Rossi ${ }^{1}$
}

Resumo: É estudada a operação interna dos tratados internacionais, assunto que envolve a hierarquia entre tratado e lei. Buscam-se os elementos teóricos para fundamentar uma decisão judicial em que exista antinomia entre tratado e lei. É utilizado o método dedutivo e a técnica monográfica. Apenas sob o aspecto de responsabilização internacional é permitido afirmar-se que o direito internacional, fundado na soberania, tem primazia sobre as ordens domésticas. As teorias que buscam descrever as relações entre direito internacional e direito interno, monismo e dualismo, principalmente, encontram várias críticas e não permitem estabelecer definitivamente a discussão. $O$ direito internacional permite aos países liberdade de organização, inclusive no que se refere à operação interna dos tratados, desde que isso não prejudique a boa-fé na sua execução. As constituições, ao tratar da operação interna dos tratados, devem regular especialmente: aplicação direta, vigência interna e hierarquia entre tratado em normas positivas internas (constituição e leis ordinárias).

Palavras-chave: Tratado internacional. Lei. Hierarquia. Aplicação direta. Vigência.

\section{INTRODUÇÃO}

As relações internacionais têm sido objeto de um número maior de estudos no Brasil em função do aumento da importância do comércio internacional. Com a circulação de merca-

1 Especialista em Direito Público - UnB. Procurador Federal. E-mail: juliano.rossi@ agu.gov.br 
dorias e de pessoas, surge a necessidade de que o sistema legislativo brasileiro esteja preparado para essa realidade. A constituição brasileira, ainda que seja criticada por ser muito analítica, repetitiva e alçar ao nível constitucional matérias, em princípio, de lei ordinária, deixou de disciplinar a relação entre direito interno e direito internacional, criando uma lacuna pouco compreensível para os dias de hoje. A operação interna dos tratados, em função da própria matéria, tem componentes que muitas vezes escapam a uma abordagem estritamente jurídica, envolvendo elementos de organização e teoria do estado e, principalmente, de política externa. Isso constitui desafio ainda maior, pois o discurso científico muitas vezes será utilizado para embasar ideologias políticas ou simpatias ocultas.

O tema das relações entre direitos domésticos e direito internacional vem sendo discutido nos tribunais e na academia há mais de um século. Triepel lançou as bases do que viria a ser conhecida como teoria dualista, que afirma a separação fundamental entre as duas ordens, na última década do século XIX. Kelsen, duas décadas depois, veio a dar forma à idéia da unidade do direito público, com sua teoria monista. No Brasil, a doutrina é predominantemente internacionalista, mas não vê nos tribunais a mesma convicção.

Este visa estudar a operação interna dos tratados, principalmente no que se refere à hierarquia entre tratado internacional e lei ordinária. Com isso, buscam-se estabelecer elementos pelos quais se pode embasar uma decisão judicial em que existem tratados e leis regulando a mesma matéria. Constitui-se a pesquisa, então, fundamentalmente dogmática. Serão vistos, mesmo assim, aspectos teóricos relacionados como os fundamentos jurídicos da ordem internacional e dos tratados e algumas das teorias sobre o relacionamento entre o direito internacional e o direito nacional dos estados.

A primeira seção tratará dos aspectos jurídicos do direito internacional e a relação entre estados, com ênfase na responsabilidade internacional. Isso visa a contextualização acerca do 
sistema internacional e as formas que este possui de estabelecer a sanção ou de promover o ajuste de conduta dos estados no caso de descumprimento de obrigações internacionais. A operação interna dos tratados será o assunto da segunda seção. Inicialmente, o tema será estudado em seus aspectos teóricos, a partir das principais teorias existentes sobre a relação entre direito internacional e direito interno. Aqui, o foco estaria na díade dualismo/monismo com seus erros e acertos. $\mathrm{O}$ aspecto prático será visto na seqüência com o estudo dos aspectos constitucionais relativos à operação interna dos tratados. $\mathrm{O}$ método empregado é o dedutivo e a técnica, monográfica.

\section{ORDEM JURÍDICA INTERNACIONAL E TRATADOS INTERNACIONAIS}

O direito internacional (DI) funda-se sobre bases diferentes das do direito doméstico. ${ }^{2}$ No direito doméstico, os indivíduos são compulsoriamente sujeitos à jurisdição do estado - ou de uma sociedade particular - que os tutela. O estado monopoliza a distribuição da justiça e é dotado de órgãos especificamente criados para darem efetividade às decisões que compõem o direito. A subordinação jurídica do indivíduo é um dos principais elementos subjacentes à idéia do direito dentro do estado. Tal não ocorre na relação entre as nações. Historicamente, a formação de grupos humanos independentes tornou necessária a existência de certas normas ou princípios jurídicos que regulassem o contato entre tais grupos, forjando um núcleo normativo cuja eficácia e amplitude variava em razão dos seus estágios de desenvolvimento e cultura. $\mathrm{O}$ requisito material para a existência de uma ordem jurídica internacional foi e continua sendo a coexistência de entes políticos organizados sobre um território não subordinados a nenhuma autoridade superior.

2 Neste estudo, os termos direito interno, direito nacional e direito doméstico serão considerados sinônimos. 


\section{1 problema da subordinação das ordens internacional e doméstica}

A soberania, ou a ausência de subordinação como a do indivíduo ao estado, é um dos elementos chave para a compreensão do DI. Em função de suas peculiaridades, o DI teve contestada a sua condição como real "direito" por vários autores. Para Kelsen (1998a, 1998b), por exemplo, que caracteriza o direito como ordem coercitiva, a carência absoluta de um órgão particular encarregado de aplicar normas jurídicas e, conseqüentemente, de sanções, evidencia que o DI é um direito primitivo. Ele seria caracterizado pela técnica jurídica da iniciativa individual, podendo ser interpretado da mesma forma que uma ordem jurídica caracterizada pela instituição da vingança de sangue (vendetta). Num sistema como esse, ainda que o ato coercitivo seja realizado como empreendimento da execução da ordem jurídica, a descentralização na aplicação do direito não impede que o ato coercitivo, como tal, seja estritamente monopolizado. Hart (1994), por sua vez, não negava a juridicidade do DI, mas afirmou que o DI somente poderia ser considerado "direito" por uma analogia ao direito interno. Essa analogia seria, todavia, de conteúdo e de função, mas nunca de forma, e assim permaneceria até que fosse geralmente reconhecido que existem tratados - como os grandes tratados multilaterais - com feição de atos legislativos, que vinculariam estados que dele não são parte.

O DI "pressupõe a existência de ordens jurídicas estatais que se autodeterminem, de sorte que não poderia conter norma alguma susceptível de suprimir a existência ou desfazer a autonomia de tais ordens" (BOSON, 1996, p. 177). Dois dos aspectos formais mais característicos desse ordenamento são o voluntarismo e o relativismo, ou seja, a extraordinária relevância do consentimento do estado tanto na criação como na aplicação das normas internacionais. As peculiaridades da estrutura da sociedade internacional e do direito que a regula irão, 
logicamente, determinar as consequências jurídicas dos tratados internacionais. Essas consequências, entretanto, não repercutem apenas no plano internacional. Os tratados implicam obrigações de comprometimento total do estado, muitas vezes visando criar reflexos no direito interno. Como bem se vê, constitui um desafio estabelecer os efeitos dos tratados no direito interno quando se busca a coerência de duas ordens essencialmente diferentes entre si.

Escapando um pouco da solução positivista, Vallejo (1999) propõe que, ainda que existam sanções em DI, não é possível fundá-lo em seu aspecto coercitivo. Ele baseia-se na Sociologia do Direito, de Weber, para entender o DI em sua eficácia empírica, de modo que a obrigatoriedade das normas não derivaria de um sistema formal de criação de normas, mas de certas garantias de provável eficácia e efetividade. Sendo assim, a principal razão da obediência a um sistema de normas seria menos o receio da sanção do que o da existência de interesses e incentivos compartilhados. Dessa forma, a ausência da centralização da aplicação de sanções não prejudica a juridicidade da ordem internacional nem deve ser superestimada. ${ }^{3}$

O direito imperativo (jus cojens), apesar ter seu fundamento político contestado, ${ }^{4}$ representa talvez a pedra angular da subordinação entre ordens internacional e doméstica. Os países e a sociedade internacional, ciosa da soberania dá forma a ela, não se interessam por anular normas domésticas de outros países, algo que se considera questão interna. $O$ contencioso internacional é de reparação, não de anulação. Nem poderia ser de outra forma, visto que não há jurisdição entre estados soberanos e iguais (par in parem non habet judicium). ${ }^{5}$ É o que se compreende do art. 27 da Convenção de Viena sobre Direito

3 Nesse particular, com ele parecem concordar Hart (1994), Boson (1996) e Mello (2000).

4 A implementação de normas imperativas em DI tem sido contestada, considerando a relatividade das normas internacionais. De fato, já foi apontada a imprecisão do conteúdo e a obscuridade das suas consequências jurídicas (cf. VALLEJO, 1999, p. 69; REZEK, 1998, p. 119-120; e REUTER, 1999, p. 168-173).

5 cf. art. $2 .^{\circ}, \S 7 .^{\circ}$, Carta da ONU. 
dos Tratados (1969):6 "Uma parte não pode invocar as disposições de seu direito interno como justificativa para o inadimplemento de um tratado" (BRASIL, 2009).? O DI toma as decisões dos parlamentos ou tribunais nacionais simplesmente como fatos que expressam a vontade e constituem atividades do estado, da mesma forma como com os atos administrativos (O'CONNELL, 1965). Em boa medida, o DI é indiferente aos direitos internos, pois os padrões de conduta a serem observados entre países, ou seja, as normas jurídicas internacionais bastam a si mesmas; o DI tem fontes próprias independentes.

O princípio básico da responsabilidade internacional é bastante simples: o estado que, ao descumprir uma obrigação internacional, causa dano a outro estado deve a ele uma reparação adequada. Essa ideia guarda bastante semelhança com a de responsabilidade extracontratual do direito civil. A responsabilidade internacional não apresenta desenvolvimento semelhante ao direito dos tratados, já codificado. É geralmente aceito, entretanto, que a responsabilidade internacional tem natureza compensatória e implica duas conseqüências: o da reparação e o da satisfação, eventualmente. A reparação está relacionada a danos materiais, implicando o restabelecimento das coisas ao estado anterior ou em sua primitiva integridade. Não sendo isso possível, ou somente o sendo parcialmente, caberia uma indenização da quantia equivalente. A satisfação, por outro lado, relaciona-se a danos imateriais e faz-se geralmente por meio de atos expiatórios, como o pedido de desculpas ou a punição dos culpados.

É importante perceber a responsabilidade internacional decorrente de atos legislativos ou judiciais nacionais não signi-

6 Promulgada pelo Decreto n. 7.030, de 14 de dezembro de 2009.

70 texto do art 27 termina da seguinte forma: "Esta regra não prejudica o artigo 46". $\mathrm{O}$ art. 46 trata da nulidade de tratados, e tem a seguinte redação: "Um Estado não poderá invocar o fato de que seu consentimento em obrigar-se por um tratado foi expresso em violação de uma disposição de seu direito interno sobre competência para concluir tratados, a não ser que essa violação seja manifesta e diga respeito e diga respeito a uma regra de seu direito interno de importância fundamental [sem grifo no original]." Como bem se vê, possui âmbito de aplicação bastante restrito. 
fica a ingerência sobre assuntos de domínio exclusivo dos estados, visto que nenhum desses atos será anulado. Existe, sim, a compensação por um dano decorrente da violação de uma norma internacional, ou, em outros termos, da inexecução de uma obrigação assumida segundo o DI.

\subsection{Os tratados internacionais}

Tratado é o ato jurídico formal regido pelo DI pelo meio do qual se manifesta o acordo de vontades entre duas ou mais pessoas internacionais. Reuter (1999, p. 45, tradução nossa) o define como "uma manifestação de vontades concordantes, imputável a dois ou mais sujeitos de direito internacional, e destinada a produzir efeitos jurídicos em conformidade com as normas de direito internacional". $\mathrm{O}$ tratado não dispensa certa formalidade. De fato, a Convenção de Viena, em seu art. 2, $\S 1 .^{\circ}$, letra "a", prevê ser o tratado "um acordo internacional celebrado entre estados em forma escrita [sem grifo no original] e regido pelo direito internacional (...) qualquer que seja sua denominação específica” (BRASIL, 2009). Em seu art. 3. ${ }^{\circ}$, letra "a”, entretanto, prescreve que os acordos internacionais não celebrados por escrito ainda assim terão valor jurídico. ${ }^{8}$

Tratados internacionais, fundamentalmente, têm natureza obrigacional, tais como os contratos. Aplicam-se àqueles os mesmo princípios básicos deste, ou seja, a autonomia da vontade e o pacta sund servanda. Para Reuter (1999, p. 38, tradução nossa),

o tratado vincula os estados porque estes consentiram em vincular-se por ele. Portanto, o tratado é um ato jurídico no qual intervém vontades humanas e por esta razão podemos falar a este propósito do mecanismo convencional ou de seu caráter operativo. A palavra "tratado", então, inclui tanto o ato como seu resultado, a saber, a norma.

8 Os Estados, ainda assim, resistem à ideia de informalidade dos tratados (REUTER, 1999, p. 46). 
Não haveria nenhum ato se não engendrasse uma norma, assim como a norma não poderia existir senão como resultado de um ato. Portanto, não é possível separar o ato da norma, se bem que seja necessário distinguir um da outra.

Essa distinção não deixa de ter conseqüências. Ao se privilegiar o ato (como no contrato) a interpretação do tratado seria dada pela intenção das partes. Nesse caso, entretanto, existe dificuldade em se estabelecer critérios para solucionar normas contraditórias, pois, em função do relativismo das normas convencionais, não existe razão para que um tratado prevaleça sobre outro. Por outro lado, ao se privilegiar a norma (objeto), talvez seja possível estabelecer uma hierarquia entre tratados. Da mesma forma, existem reflexos sobre a teoria das nulidades. Ao privilegiar-se o ato, os vícios de consentimento devem ser interpretados amplamente, pois é só no consentimento que se baseia o tratado. Por outro lado, privilegiando-se a norma, se restringirá a possibilidade de nulidade em virtude das necessidades legislativas da sociedade internacional. A distinção entre ato e norma relaciona-se em grande medida com outra díade: contrato e lei.

A forma de expressão do consentimento do estado é, basicamente, convencionada, podendo tomar formas mais ou menos expeditas dependendo da importância da adoção de procedimentos extensos ou breves. A Convenção de Viena, em seu art. 11, prevê que um estado pode manifestar o consentimento em obrigar-se por um tratado pela assinatura, troca dos instrumentos constitutivos do tratado, ratificação, aceitação, aprovação ou adesão, ou, ainda, por quaisquer outros meios acordados (BRASIL, 2009). Como se pode perceber dos termos utilizados, é certo que, expresso o consentimento, um tratado passa a ser um compromisso internacional consumado em termos definitivos e perfeitos - irretratável, portanto. A assinatura, além de seu caráter de fixação e autenticação do texto do 
tratado, servirá também como expressão definitiva do consentimento se assim dispuser o tratado (art. 12, § 1.॰, "a”, Convenção de Viena). Segundo Accioly e Silva (1996), a prática internacional admitia que alguns tratados de menor importância não exigiam ratificação. A orientação, contudo, alterou-se e atualmente essa regra pode estender-se a todos os tratados, considerando a praxe entre os países da Comunidade Europeia (hoje União Europeia).

Ratificação é "o ato unilateral com que o sujeito de direito internacional, signatário de um tratado, exprime definitivamente, no plano internacional, sua vontade de obrigar-se" (REZEK, 1998, p. 53). Nem sempre é exigida; é apenas necessária na celebração de tratados por procedimento extenso, que exige maior solenidade. $\mathrm{O}$ efeito jurídico da assinatura do tratado, nesse caso, seria essencialmente a autenticação do texto (art. 10, Convenção de Viena) (BRASIL, 2009). O termo ratificação, segundo Rezek (1998, p. 51-53), tem sido utilizado para significar quatro coisas distintas: a) o ato internacional de estado que exprime a vontade de se obrigar por um tratado; b) o procedimento internacional para a formação de um tratado, a troca ou depósito formal dos instrumentos de ratificação; c) o documento em que o estado exprime sua vontade de obrigar-se pelo tratado; e d) a aprovação do tratado pela legislatura ou outro órgão do estado cujo consentimento possa ser necessário. Esta última acepção é indesejável e não será utilizada aqui para significar a aprovação legislativa prevista na constituição brasileira.

A forma e a data da entrada em vigor de um tratado será como previsto no tratado ou como acordado pelas partes. Na ausência de tal provisão, entrará em vigor quando todos os estados negociadores estabelecerem seu consentimento em obrigar-se pelo tratado (art. 24, Convenção de Viena) (BRASIL, 2009). No caso de a vigência ser contemporânea ao consentimento, o tratado passa a atuar como norma jurídica no mesmo momento em que se completa o ato jurídico. É, entretanto, mais comum que a vigência seja diferida, de forma a que o tratado 
possa ser dado a conhecer no interior dos países - por administradores, juízes e cidadãos - e para que se possibilite a coincidência das vigências internacional e interna do tratado.

\section{O RELACIONAMENTO ENTRE DIREITO INTERNACIONAL E DIREITO INTERNO}

O estudo das relações entre direito internacional e direito interno envolve questões teóricas e práticas. $\mathrm{O}$ aspecto teórico envolve a construção de uma teoria jurídica que explique coerentemente o relacionamento entre o DI e o direito interno dos estados. O prático está relacionado à resolução dos problemas surgidos da aplicação de normas particulares do DI no direito interno e os eventuais conflitos entre eles, ou como preferem os autores de língua inglesa, questões decorrentes da operação interna dos tratados (internal operation of treaties).

Historicamente, é possível identificar dois períodos em que houve, no estudo do tema, o predomínio de um dos aspectos sobre o outro. Em um primeiro momento, desde o final do século XIX até a década de 30 do século passado, quando se sistematizou o problema, as discussões acerca do tema envolviam predominantemente os aspectos teóricos da matéria. Posteriormente, por pouco refletirem na realidade das relações entre os estados, passou-se a privilegiar o aspecto pragmático da matéria (GALINDO, 1999). A própria existência de uma relação entre DI e direito interno a ser estudada somente pôde ser verificada depois de satisfeitas algumas condições. Segundo Litrento (1968), apenas com o surgimento do positivismo e do voluntarismo é que o problema conformou-se, opondo DI e ordem interna, quando anteriormente vigoravam concepções universalistas e jusnaturalistas do DI.

Normalmente o estudo do relacionamento entre DI e direito interno é caracterizado pela díade monismo/dualismo (ou monista/ dualista). Esses termos, entretanto, são equívocos e merecem uma pequena advertência inicial, normalmente negligenciada. 
Por um lado, monista e dualista são teorias jurídicas de caráter científico. Tem-se aqui, como objetivo principal a descrição, não de um caso particular, mas de um conjunto inteiro de fenômenos. Mais especificamente, busca-se criar uma teoria para descrever as relações entre DI e direito doméstico não de um ou de alguns países, mas de uma universalidade de países. Aqui, os termos refletem o já mencionado aspecto teórico da disciplina.

Por outro lado, monista e dualista $a^{9}$ são também termos que caracterizariam diferentes sistemas constitucionais (políticos, então) de aplicação de normas internacionais no interior dos estados. Dessa forma, países seriam identificados como monistas ou dualistas - ou quaisquer denominações intermediárias - dependendo de como as soluções adotadas por seu direito constitucional se assemelhem às conclusões de uma ou outra das terias científicas. A concepção voluntarista, ao fundar o DI no consentimento dos estados, leva ao dualismo; a concepção objetivista, ao situar a origem do ordenamento jurídico fora da vontade humana, conduz ao monismo. Por envolver o estudo das constituições dos países, refletem, por seu lado, o aspecto prático.

Por conta disso, quando forem utilizados os termos monismo e dualismo, na medida do possível, será estabelecido precisamente de qual contexto fazem parte.

\subsection{Parte teórica}

A teoria dualista é cronologicamente mais antiga do que a monista. $\mathrm{O}$ primeiro estudo acerca da relação entre DI e direito interno foi realizado por Heinrich Triepel, em 1899, na obra Völkerrecht und Landesrecht. Em 1905, na Itália, Dionisio Anzilotti, lançou Il Diritto Internazionale nei Giudizi Interni, em que

9 Jackson aponta para a inadequação dessa terminologia, visto é que é por demais dicotômica e imprecisa. Na realidade, existem vários graus de aplicação direta de tratados, sem mencionar a confusão que existe quando se trata do assunto (JACKSON, 1992). 
desenvolve as idéias propostas inicialmente por Triepel. A denominação teoria dualista foi cunhada por Verdross - que não era dualista - em 1914; ${ }^{10}$ o termo dualismo aparece pela primeira vez em escritos de Triepel em 1923 (ARIOSI, 2000).

A teoria dualista, ao fundar-se sobre o voluntarismo e a soberania do estado, identifica-se filosoficamente com o hegelianismo. Também entendida como a doutrina do paralelismo do direito público (BOSON, 1996), afirma o DI e o direito interno como duas ordens igualmente válidas, porém absolutamente distintas e independentes. Não havendo ponto de contato, teoricamente não há o risco de conflito entre um e de outro. Basicamente, a teoria propugna a diversidade entre as fontes do DI e do direito interno. As normas de DI procedem de uma vontade comum dos estados, não podendo senão em razão dela ser modificadas ou suspensas; ao passo que as normas de direito interno emanam unilateralmente da vontade soberana do estado - somente este podendo modificá-las ou suspendê-las - e seriam incapazes de estabelecer obrigações entre estados. A lei, sendo manifestação da vontade do estado orientada para dentro, é essencialmente distinta da participação em um ato coletivo de vontade pelo qual o soberano assume obrigações em face de outros soberanos. O direito interno, então, regularia as relações entre súdito e soberano e de súditos entre si. O DI, por outro lado, referir-se-ia ao relacionamento entre soberanos e entre eles apenas.

Um sistema jurídico pode referir-se a outro por intermédio da recepção das normas do outro ordenamento. Essa recepção (mediante um ato de transformação ou de incorporação) seria responsável por uma transformação da natureza da norma em termos de: a) seu valor formal, que se faz jurídica na ordem interna; b) seus destinatários, deixando de serem estados para serem indivíduos; e c) seu conteúdo, que é mais ou menos transformado para que se dê valor extensivo interno - eficácia nacional. Sendo

10 Verdross reconheceu posteriormente a deficiência do termo, vindo a preferir denominá-la teoria pluralista, ao admitir que não existe apenas um direito interno, mas tantos quantos Estados existirem (GARCIA JÚNIOR, 1997, p. 127). 
assim, a simples ratificação do tratado não é capaz de operar essa transformação. Os possíveis conflitos decorrentes das antinomias entre normas internacionais e internas (depois de devidamente recepcionadas, logicamente) seriam resolvidas no plano internacional por intermédio da responsabilização internacional do estado sem invalidar, contudo, a norma interna.

A teoria monista surgiu da crítica à teoria dualista ao afirmar a unidade do direito público. Em vez de haver duas ordens separadas e independentes, DI e direito interno formariam uma única ordem jurídica, organizada segundo um princípio de derivação, ou subordinação, de uma à outra. Segundo seus defensores, há uma interdependência entre DI e direito interno que é o sentido da unidade do direito. Destes, Kelsen é considerado o precursor da teoria, tendo assumido posição de vanguarda, contra a opinião dominante em sua época. Ele consagra o monismo em Das Problem der Souveranitat und die Theorie des Volkerrechts, em 1920 (ARIOSI, 2000).

O monismo não chegou, todavia, a constituir um movimento homogêneo. Sob o mesmo nome reuniram-se diversos doutrinadores com concepções diversas acerca dessa unidade do direito público. Diversos também seriam os fundamentos. Com propriedade, então, pode-se falar em vertentes dentro do monismo. Boson (1996) as dispõe da seguinte forma: a) monismo jusnaturalista (com suas variantes teológica, racionalista, psicológica, sociológica e axiológica); b) monismo historicista; e c) monismo normativista (da Escola de Viena).

O monismo normativista, de Kelsen (1998a, 1998b), tem as mesmas bases de sua ciência normativa (lógico-formal, então) apresentada na Teoria Pura do Direito. Segundo tal sistema, as normas extrairiam seu fundamento de outras normas que lhes conferem validade, estas de hierarquia superior. A regressão continuaria até que se alcançasse uma norma fundamental de caráter hipotético, garantidora da validade de todo o ordenamento. Para Kelsen, com sua proposta de pureza metodológica, o elemento de conexão entre as ordens interna e internacional 
não poderia vir de elementos metajurídicos. Sendo assim, para garantir a coerência de sua teoria, enuncia simplesmente que "a unidade de direito nacional e direito internacional é um postulado epistemológico” (KELSEN, 1998a, p. 530). Sendo um único sistema, ou as duas ordens são subordinadas uma à outra ou são coordenadas entre si e ambas subordinadas a uma terceira ordem. Como esta não existe, somente resta a primeira opção. A identificação da norma fundamental do ordenamento estabeleceria, então, qual das ordens teria a supremacia. Havendo uma subordinação entre as duas ordens, interna e internacional, deve-se determinar qual das duas tem a primazia. Para Kelsen (1998a), a ordem internacional teria a primazia, articulando todo o ordenamento partindo de uma norma que poderia ser enunciada da seguinte forma: os estados devem se conduzir como têm se conduzido de costume.

Segundo Kelsen (1998a, p. 522), tal qual no direito interno, a norma hipotética fundamental deriva de um princípio de eficácia: "a ordem jurídica internacional, por meio do princípio de eficácia, determina não apenas a esfera de validade, mas também o fundamento de validade das ordens jurídicas nacionais". A invalidade das normas internas em desacordo como as normas internacionais, entretanto, não seria nunca automática. Ele observa que a "ilegalidade de uma norma significa a possibilidade de revogar a norma ou de punir o órgão criador da norma” (KELSEN, 1998a, p. 528). Para isso, tal qual no direito interno, há a dependência de que seja feito mediante um processo. Aponta, contudo, que o DI geral não estabelece esse processo por meio do qual se poderia declarar a "ilegalidade" de uma norma de direito interno, tal como ocorre no direito interno ou em algum DI particular. Segundo parece, em função da situação política internacional, assim continuará por um bom tempo. ${ }^{11}$ No plano interno, continua, se houver conflito entre disposição de tratado e de norma doméstica, o juiz estaria obrigado por sua jurisdição; se a constituição deter-

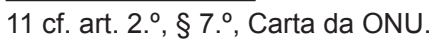


minar a prevalência da norma interna, assim deve proceder. Isso, todavia, configuraria ilícito internacional, submetendo o estado ao regime da responsabilização.

De fato as duas correntes - e as diversas teorias existentes não estão imunes a críticas. Das duas posições, a dualista é a que encontra maior crítica. Inicialmente, o voluntarismo, sua base filosófica, tem vários inconvenientes, pois tem dificuldade em explicar o fundamento do DI, especialmente a obrigatoriedade do costume internacional. Pode ser acrescentado que menos explicaria o jus cogens. Também se verifica que o DI costumeiro é normalmente aplicado pelos tribunais internos "sem que haja qualquer transformação em lei interna” (GARCIA JÚNIOR, 1997, p. 134). Do ponto de vista jurídico, o DI dirige-se ao direito nacional dos estados; se estes não o cumprem, ele deixa de funcionar. As normas de DI são incompletas e aguardam suplementação pelas normas do direito nacional. Utilizando-se de pontos de vista metajurídicos, existem ainda mais objeções, pois o dualismo exagera na distância entre ordens nacionais e internacional, ignorando a realidade universal da experiência humana. Segundo O’Connell (1965, p. 43, tradução nossa), fossem realmente ordens dissociadas, "o direito internacional e o direito domésticos seria regimes competitivos, inadequados para a solução dos problemas humanos”.

Da mesma forma, é historicamente superada a idéia de que normas de DI somente se endereçam aos estados. $\mathrm{O}$ indivíduo, mesmo não tendo ascendido à qualidade de sujeito de DI geral, pode ser de um DI particular. Existem normas importantes do DI que impõem obrigações e conferem direitos aos indivíduos de forma direta, como, por exemplo, na Declaração Universal dos Direitos do Homem. Um indivíduo pode ser responsabilizado internacionalmente pelo Tribunal Penal Internacional.

O monismo, por seu lado, também tem falhas "porque trata um sistema como derivação do outro, ignorando as realidades físicas, metafísicas e sociais que de fato as separam" (O’CONNELL, 1965, p. 43). De fato, a hierarquização formal de 
todo o sistema, proposta por Kelsen, é dificilmente verificável. Ao apoiar a norma fundamental (hipotética) num princípio de eficácia (factual), continua padecendo dos mesmos defeitos da teoria pura do direito. Saindo do domínio puramente normativo, por outro lado, ao se estabelecer a supremacia de uma ordem sobre a outra, está-se fazendo um juízo de valor a priori. Essa escolha apriorística, contudo, não garante que a ordem prestigiada tenha maior valor ou seja mais justa do que a outra no caso concreto. ${ }^{12}$ Numa situação como essa, ou mantém-se a escolha inicial, com o risco de haver uma solução injusta, ou dá-se primazia à outra ordem. Nesse caso, porém, não se pode dizer que existe subordinação de uma ordem à outra, mas uma subordinação das duas ordens a uma terceira, uma solução de contornos claramente jusnaturalistas.

Em adição a tudo isso, nenhuma das duas correntes responde de forma satisfatória a outras questões práticas relacionadas, como a questão da interpretação dos tratados por tribunais nacionais ou o valor da jurisprudência internacional nesses tribunais.

Algumas teorias alternativas buscaram resolver os problemas das antecessoras. Essas, contudo, segundo Celso Albuquerque Mello (2000), não tiveram repercussão expressiva. A teoria da harmonização, todavia, merece algum destaque por se ocupar de um aspecto prático negligenciado nas teorias apresentadas, ainda que ela não tenha sido citada por nenhum dos autores brasileiros pesquisados. A teoria da harmonização propõe uma visão intermediária entre os extremos monista e dualista, que não descreveriam a realidade adequadamente. Conforme O'Connel (1965, p. 44), as antinomias não implicam invalidade de uma das normas ou que os sistemas que os sistemas que as produziram sejam mutuamente incompatíveis. É uma das funções do raciocínio jurídico eliminar contradições pela harmonização dos pontos de colisão, não por fingir que

12 O'Connell (1965, p. 41) cita o caso de Verdross, cujas razões pelas quais colocou o direito internacional sobre os direitos nacionais dos Estados não são claras, desconfiando que se relacionem ao desejo do jurista por um mundo regido pelo direito. 
eles não existem nem colidindo-os um contra o outro. Dessa forma, um juiz internacional ou doméstico, devendo expressar a unidade fundamental que todo o direito possui, e devendo objetivar harmonizar normas que possuem diferentes origens formais, mas sobrepõem-se em operação, ${ }^{13}$ não possuem um mandato a priori para tratar um ou outro sistema superior em valor normativo. A teoria da harmonização assume que o direito internacional, "como uma regra de comportamento humano, forma parte do direito doméstico e, sendo assim, está disponível ao juiz nacional; mas, nos raros casos de conflito entre os dois sistemas, essa teoria reconhece que ele está obrigado por suas regras jurisdicionais" (O'CONNELL, 1965, p. 45).

Se um Estado estrangeiro vai além dos limites de ação previstos pelo direito internacional, seus atos não têm valor legal aos olhos do direito internacional. Eles somente têm valor legal para o juiz daquele Estado estrangeiro cuja constituição prescreve que ele deve aplicar o direito doméstico quando ele colide com o direito internacional. Sendo assim, considerando as regras da harmonização, pode-se construir o raciocínio de que existe uma presunção - que poderá variar, dependendo do sistema constitucional - de que o Legislativo não tem a intenção de derrogar normas internacionais. Isso permite admitir que a interpretação legal deve ser tal a eliminar conflitos e permitir que as normas sejam harmonizadas. Quando, contudo, a intenção de derrogar normas internacionais é claramente discernível no próprio ato, o juiz estará vinculado por sua jurisdição e dará o efeito previsto por seu direito constitucional.

\subsection{Parte prática}

A questão da hierarquia entre lei e tratado é apenas umas das diversas questões constitucionais envolvendo tratados e

13 O'Connell (1965, p. 45, tradução nossa) descreve muito bem essa situação quando afirma que "o juiz, quando em face de um conflito entre direito internacional e direito doméstico, está na presença de dois textos de origens formais distintas, mas que sustentam possuir o mesmo substrato jurídico para seu valor legal." 
direito nacional. É, contudo, a que ocupa as maiores preocupações dos autores brasileiros, que a tomam por central, pouco se ocupando de outros assuntos igualmente relevantes. Ainda que o objetivo neste estudo seja apenas a questão hierárquica, existem outros temas correlatos que precisam ser também tratados de forma a poder compreender-se essa hierarquia.

Jackson (1992), em vez de inferir se um país se enquadra nas categorias tradicionais monista ou dualista ${ }^{14}$ prefere enumerar as questões a serem resolvidas pelos seus sistemas constitucionais. Ele inclui entre as principais questões envolvendo tratados no direito nacional as seguintes: (a) o poder de negociar o tratado; (b) o poder de assinar o tratado (normalmente ad referendum, apenas para autenticar o texto); (c) o poder de manifestar consentimento em obrigar o país pelo tratado; (d) a validade do tratado em face do direito constitucional e sua vigência; (e) o poder de implementar as obrigações do tratado; (f) aplicação direta do tratado no direito nacional; (g) a invocabilidade do tratado; (h) hierarquia de normas no direito nacional quando há conflito entre normas do tratado e normas de direito interno; (i) o poder de administrar (administer) o tratado, que inclui uma série de questões como o procedimento formal de ratificação; o poder de interpretar o tratado para aplicação doméstica e em termos de DI; o poder de representar o país nos procedimentos institucionais relacionados ao tratado (como em reuniões bilaterais ou multilaterais); o poder de votar em tais procedimentos; o poder de emendar um tratado; e o poder de denunciar o tratado.

Não é objetivo deste estudo uma análise completa de todos esses pontos. Os pontos de maior interesse são os que envolvem a operação interna dos tratados, ou seja, a aplicação direta (AD), a vigência, a invocabilidade e a hierarquia. Os efeitos relativos à operação interna dos tratados somente podem ser apreciados seqüencialmente; para que se possa passar ao ponto seguinte, deve haver uma afirmativa no anterior. Sendo assim, a questão

14 Vide nota 10. Desta parte em diante, os termos monista e dualista aparecerão sempre entre aspas. 
hierárquica somente será apreciada se o tratado: (a) for válido segundo ambos DI e direito doméstico; b) for diretamente aplicável; c) estiver vigente domesticamente e d) for invocável pela parte interessada.

O primeiro dos temas referentes às provisões constitucionais acerca dos tratados no direito interno é o da operação interna dos tratados. Normalmente a questão não é tratada pelos doutrinadores brasileiros nestes termos. Nem por isso deixa de ter relevância, pois determinará, em última análise, se o Brasil adota a solução "monista" ou a "dualista". Um país "monista" seria aquele que privilegia a aplicação direta. Num "dualista", haveria a necessidade de um ato de transformação (ou ato de incorporação) para que os tratados tivessem operação dentro do país.

Os termos devem ser definidos precisamente, pois podem ser origem de equívocos. Aplicação direta significa que os tribunais e os órgãos administrativos assumirão o tratado diretamente como fonte do direito, tratando seu texto exatamente da mesma forma como se fosse o de uma lei. ${ }^{15}$ Desta forma será entendido o termo neste estudo. Com relação à $\mathrm{AD}$, O'Connell (1965) estabelece ainda uma distinção necessária entre tratados auto-executório (self-executing) ${ }^{16}$ e não auto-executórios (non self-

15 Convém lembrar que a mesma terminologia é também utilizada para a qualificação de algumas características de normas supranacionais. Aplicabilidade direta (em espanhol aplicabilidad inmediata o automática), seria a qualidade das normas supranacionais de se incorporarem automaticamente à ordem jurídica dos Estados-membros, sem necessidade de qualquer ato estatal que as recepcione. Também não se deve confundir com o efeito direto (em espanhol aplicabilidad direta), outra qualidade das normas supranacionais, que confere direitos e obrigações diretamente aos cidadãos dos Estados-membros. Ainda que isso seja mais bem explicado mais adiante, o efeito direto, na terminologia adotada aqui, decorreria de um tratado diretamente aplicável e invocável.

16 O'Connell estabelece uma natureza dual do termo auto-executório, que terá conotações diferentes nas ordens internacional e nacional. Ao tratar da operação dos tratados no interior dos países, afirma que, quando a constituição autoriza os tribunais a aplicar o tratado diretamente, estar-se-ia diante de um tratado auto-executório em direito doméstico (self-executing in municipal law). Em direito internacional, auto-executório (self-executing in internacional law) seria a qualidade do tratado o qual não necessita de nenhuma provisão adicional para que tribunais internacionais possam aplicá-lo (op. cit., p. 57-58). Como se percebe, as definições com base na aplicação pelos tribunais revela uma característica de common law. 
-executing). Estes últimos teriam apenas a intenção de obrigar externamente, sujeitando os países apenas à responsabilização internacional e não sendo capazes de vincular diretamente no interior dos países. A diferenciação entre um e outro estaria na intenção das partes e da linguagem do tratado. Tratados não auto-executórios necessitariam, dessa forma, de atos legislativos internos posteriores para concretizar o propósito do tratado. Logicamente, somente esses atos poderiam ser invocados em um tribunal nacional. ${ }^{17}$ Para se utilizar uma terminologia mais familiar, tratados não auto-executórios seriam aqueles em que seus dispositivos não seriam auto-aplicáveis.

Invocabilidade ou aplicação direta parcial (ADP), por seu lado, está estreitamente ligada com a AD e relaciona-se a quem pode invocar o tratado. Talvez mais bem colocado, atua sobre âmbito de aplicação da norma convencional. Jackson (1992) observa que, por exemplo, um tratado pode ser diretamente aplicável numa disputa entre diferentes níveis de governo, ou entre governo e cidadãos (verticalmente), mas não entre cidadãos (horizontalmente).

Se não se adota a $\mathrm{AD}$, tem-se que o texto do tratado não será invocável num tribunal do país de forma alguma pela parte interessada. Havendo sido editada lei que dispuser sobre a matéria contida no tratado, será ela, e somente ela, invocável. Tal lei seria o ato de transformação, termo utilizado pelos dualistas para caracterizar o ato legislativo previsto na constituição do estado que conferiria direitos e obrigações com aspecto de obrigatoriedade, generalidade e abstração (definição de lei), posto que o tratado, como ato meramente internacional (entre estados), não teria essa capacidade. No interregno entre a vigência do tratado no âmbito internacional e a vigência da lei interna que o regulamenta, não há direito invocável internamente, ainda que o país esteja sujeito à responsabilização internacional. Interessante é notar que num sistema como esse, não há lugar para discutir-se sobre hierarquia, visto que o tratado não faz parte do 17 op. cit., 55-56. 
acervo normativo nacional. As leis que internalizam o texto do tratado seriam leis ordinárias tais quais outras leis ordinárias, ou seja, estariam no mesmo nível hierárquico. Estariam sujeitas, portanto, aos mesmos critérios em caso de conflito. Como exemplo paradigmático, pode-se citar o caso da Inglaterra. A Coroa tem como prerrogativa exclusiva a celebração de tratados, incluindo a ratificação, não havendo participação formal do Parlamento nesse processo. Em compensação, tratados nunca têm AD, necessitando que o Parlamento edite uma lei, que poderá, inclusive, repetir exatamente os termos do tratado. Somente tais leis poderiam ser aplicadas pelos tribunais.

Tendo o tratado AD, deve-se perquirir sobre o termo de início de vigência no interior do país. Para Rezek (1998), os estados, como entes soberanos, podem diferir a vigência interna dos tratados, desde que isso não prejudique a boa-fé na sua execução. Sendo assim, a menos que haja algum tipo de restrição constitucional, os tratados devem entram em vigor simultaneamente nas órbitas internacional e doméstica. A doutrina normalmente se refere a essa possibilidade como recepção imediata ou aplicabilidade imediata. O'Connell (1965), por outro lado, contesta essa visão no que se refere à obrigação dos cidadãos. Para ele, sendo o tratado um contrato, e não lei, estabelece apenas regras para as partes pactuantes, que devem ser promulgadas para o indivíduo antes que elas o obriguem. Sendo assim, com o início da vigência internacional, apenas os governos estariam obrigados pelo tratado. A vigência interna estaria a depender de um ato do estado que a estabelecesse. Ainda que existam países que adotem a recepção imediata, como os Países Baixos, de 1906 a 1953 (REZEK, 1998), usualmente se promulgam os tratados de alguma forma (por lei ou decreto) ou, senão, pela simples publicação oficial, antes que possam vincular indivíduos.

Antes de iniciar propriamente a discussão acerca da hierarquia entre tratado e fontes internas, deve-se primeiro delimitar o alcance do termo hierarquia, visto que, no presente contexto, 
ele pode se tornar equívoco. No plano lógico-normativo da teoria positivista, o direito regula a sua própria criação. Uma norma é apenas válida se criada segundo determinação de forma e conteúdo de outra norma que a antecede. Sendo assim, tem-se nesta o fundamento de validade daquela. A norma que determina a criação de outra norma é a norma superior e a norma criada segundo essa regulamentação é a norma inferior. A relação entre normas superior e inferior é uma relação hierárquica. No que se refere ao tratado internacional, não existe relação de hierarquia propriamente dita. $\mathrm{O}$ tratado não busca na constituição seu fundamento de validade. Por ser uma norma de DI, é neste que o tratado busca seu fundamento de validade, não no direito interno. Mesmo que a constituição outorgasse maior autoridade ao tratado do que à lei ordinária no âmbito interno, ainda assim não haveria hierarquia. $O$ tratado continuaria buscando seu fundamento de validade no DI.

Sendo assim, deve-se entender hierarquia no contexto deste estudo de forma um pouco mais frouxa, significando a autoridade que goza, no interior de um estado, o tratado de afastar a aplicação de outra norma antinômica interna, que poderia ser norma constitucional, lei federal, constituição ou lei estaduais ou outras, mesmo de níveis inferiores, como decretos ou resoluções. Como essa autoridade não pode ser deduzida do ordenamento, pois as origens formais são diversas, ela deve ser obrigatoriamente outorgada. O instrumento idôneo para isso em matéria de direito interno seria a constituição.

Relembre-se que, no plano internacional, não se cogita, ao menos na atualidade, da possibilidade de que normas convencionais revoguem normas internas. Não é verdade, entretanto, que o DI não preveja a existência de alguma hierarquia entre normas internas e convencionais, pois poderá haver responsabilização internacional caso as obrigações não sejam cumpridas. Dessa forma, o DI, mesmo não exigindo que tratados estejam no topo da pirâmide, ainda assim reivindica certa autoridade às normas internacionais. 
De qualquer sorte, é na existência de antinomias que o problema da hierarquia surge. Em se dando valor à questão da harmonização, entretanto, o alcance da palavra antinomia também deve ser redefinido. Os critérios de solução de antinomias visam precipuamente a eliminação de uma das normas segundo o seguinte raciocínio: se duas normas são contraditórias, uma delas deve ser afastada. De acordo com os princípios da harmonização, por outro lado, se há conflito, ambas devem prevalecer por intermédio de uma conciliação, desde que isso seja possível. Bobbio (1997) chamaria essa operação de interpretação corretiva. ${ }^{18}$ Com um pouco mais de ousadia, e dependendo da situação, talvez essa harmonização seja possível via método interpretativo de concretização, tal qual com normas constitucionais. ${ }^{19}$

Dessa forma, antinomia deve ter uma acepção mais restrita, significando, segundo Jackson (1992), uma norma de tratado inevitavelmente inconsistente com normas domésticas. Como as constituições são usualmente reputadas superiores aos tratados, a questão chave seria determinar a autoridade de um tratado quando há conflito com lei posterior. Em constituições que outorgam maior autoridade aos tratados, seria afastada a aplicação da lei no que fosse contrária. Se, por outro lado, não houver prevalência de um sobre o outro, costuma-se utilizar o princípio lex posterior derogat priori, como se estivessem no mesmo nível hierárquico.

Como paradigma da $\mathrm{AD}$ com status superior dos tratados ${ }^{20}$ (ADSS), tem-se a Holanda. Com efeito, um tratado pode

18 cf. BOBBIO, Norberto. Teoria do ordenamento jurídico. 10 ed., Brasília : UnB, 1997. p. 97-105.

19 O método interpretativo de concretização é um método tópico de interpretação, que afirma não ser possível a interpretação da constituição sem problemas concretos. A determinação do sentido da norma e a sua aplicação a um caso concreto constituem um processo unitário, que pressupõe uma compreensão prévia do ordenamento vinculada a um caso concreto que se busca solucionar. Pelo princípio da unidade da constituição, que considera que nenhuma norma constitucional pode ser interpretada em contradição com outra norma da constituição, a concretização se materializa pela proporcionalidade, de modo a conciliar direitos fundamentais aparentemente antagônicos. Cf. BONAVIDES, Paulo. Curso de Direito Constitucional. 11 ed. São Paulo : Malheiros, 2001. p. 446-480.

20 "monismo internacionalista" ou "monismo radical", caso seja preferido. 
mesmo derrogar parte da constituição. Para isso basta que seja observado procedimento especial - ainda assim, menos rigoroso do que o para aprovar emenda constitucional - na sua aprovação pelo parlamento (art. 91, § 3.`). Não há, da mesma forma, controle de constitucionalidade de tratados (art. 120). Os tratados obrigariam internamente na data de sua publicação no país (arts. 93 e 95).

\section{CONCLUSÃO}

A sociedade internacional funda-se na igualdade soberana dos estados. Isso não significa, contudo, que estes possam agir de forma totalmente livre ou sem freios. Os estados organizam-se de forma a constrangerem-se uns aos outros não só pela força, mas também por meio de obrigações livremente assumidas, os tratados, ou por meio do costume. A existência de um direito internacional, todavia, não poderia ser explicado somente com base nas sanções impostas pela comunidade internacional, mas também pela materialização de objetivos compartilhados. Com o desenvolvimento das organizações internacionais e dos grandes tratados multilaterais, a sociedade internacional vem presenciando uma crescente institucionalização e um incremento na limitação do campo de ação de seus membros. Dito de outra forma, os estados olham-se muito mais de perto hoje do que antigamente.

$\mathrm{O}$ contencioso internacional que, na atualidade, continua sendo de reparação, tem na responsabilidade internacional seu fundamento. Esse sistema de responsabilização, ainda que pouco desenvolvido, permite se afirmar que o direito internacional tem primazia sobre os direitos nacionais, na medida em que constitui a última esfera de discussão judicial. É um sistema não universal, contudo, pois restringe o acesso de indivíduos - não reconhecidos como pessoas de direito internacional geral - a menos que recorram à proteção diplomática. Disso se depreende que os estados continuam resistentes à idéia de que 
questões internas venham a ser discutidos em tribunais internacionais. Essa separação entre direito interno e direito internacional, imposta pelos estados, acabará se refletindo nas teorias que visam explicar as relações entre as duas esferas.

As teorias que buscam descrever as relações entre direito internacional e direito interno, monismo e dualismo, principalmente, encontram várias críticas e não permitem estabelecer definitivamente a discussão. As teorias como formuladas por Triepel e por Kelsen são as mais bem estruturadas e coerentes, pois buscam uma descrição de forma, não apenas de função ou conteúdo. A proposta de uma harmonização entre as duas ordens, antes de se constituir uma teoria completa, visa um ajuste necessário entre elas, de forma a fornecer soluções práticas, algo que as teorias anteriores não eram capazes de fazer. Ainda, todavia, que se argumente que a teoria pouco interfere nos negócios dos estados, a inexistência de uma formulação teórica adequada é responsável por soluções práticas pouco adequadas, gerando controvérsia entre os países. Nesse aspecto, sim, seria necessário um estabelecimento definitivo da teoria, algo, entretanto, que perdeu muito de seu prestígio com o passar do tempo.

O direito internacional permite aos países a organização interna que lhes seja mais adequada, inclusive no que se refere à operação interna dos tratados, desde que isso não prejudique a boa-fé na sua execução. Sendo assim, a solução para os problemas da operação interna dos tratados será encontrada nas constituições dos países, não nas formulações teóricas. A boa-fé, como é um conceito fluido, deve ser cuidadosamente avaliada pelos estados no momento em que estes constituem seus procedimentos internos. De qualquer forma, a exigência da boa-fé faz com que o direito internacional reivindique alguma autoridade aos compromissos internacionais. A vigência interna dos tratados, por exemplo, pode ser diferida, de modo a permitir o conhecimento do tratado pela burocracia e pelos cidadãos. Até que ponto pode haver esse diferimento sem que haja má-fé, é uma questão em aberto. 
As constituições devem estabelecer várias questões envolvendo tratados, tanto relativas à competência para praticar determinados atos quanto à operação interna dos tratados. Desta, destacam-se a aplicação direta, a invocabilidade, a vigência interna e a hierarquia. Sendo assuntos constitucionais, logicamente, envolvem questões políticas que devem ser criteriosamente avaliadas antes de serem adotadas. No Brasil, como a Constituição deixa em aberto boa parte de tais assuntos, há amplo espaço para o debate, também influenciado por questões políticas. A doutrina brasileira se inclina pela aplicação direta com status superior dos tratados, o que indica maior confiança nas instituições internacionais do que nas domésticas.

Abstract: The internal operation of international treaties, particularly the hierarchy between treaty and laws enacted by parliament is studied. This articles presents theoretical models to provide basis for the solution of antinomies between treaty and laws. The deductive method and the monographic technique are used. Only from the point of international responsibility it is allowed to say that international law, founded on sovereignty takes precedence over domestic orders. Theories which attempt to describe the relationship between international and domestic law, monism and dualism, do not allow to establish definitively the discussion. International law allows countries freedom of organization, including with regard to the internal operation of treaties, provided that this does not harm the good faith in implementing the treaty obligations. Constitutions, regarding the internal operation of treaties, should provide for in particular: direct application, invocability, validity and hierarchy between treaty and laws enacted by parliament.

Keywords: International treaty. Law. Hierarchy. Direct application. Validity. Invocability. 


\section{REFERÊNCIAS}

ARIOSI, Mariângela. Conflitos entre tratados internacionais e leis internas: o judiciário brasileiro e a nova ordem internacional. Rio de Janeiro : Renovar, 2000.

ARON, Raymond. Paz e guerra entre as nações. 2 ed. Brasília : Universidade de Brasília, 1986.

BOBBIO, Norberto. Teoria do ordenamento jurídico. 10 ed. Brasília : UnB, 1997.

BONAVIDES, Paulo. Curso de Direito Constitucional. 11 ed. São Paulo : Malheiros, 2001.

BOSON, Gerson de Britto Mello. Constitucionalização do direito internacional: internacionalização do direito constitucional, direito constitucional brasileiro: os caminhos da paz. Belo Horizonte : Del Rey, 1996.

BRASIL. Decreto n. 7.030, de 14 de dezembro de 2009. Promulga a Convenção de Viena sobre o Direito dos Tratados, concluída em 23 de maio de 1969, com reserva aos Artigos 25 e 66. Disponível em: <http:// www.planalto.gov.br/ccivil_03/_Ato2007-2010/2009/Decreto/D7030. htm>. Acesso em: 30 jun. 2014.

GALINDO, George Rodrigo Bandeira. Reforma constitucional e o problema da superioridade hierárquica dos tratados frente leis internas. Cadernos de direito constitucional e ciência política, São Paulo, v. 7., n. 27, p. 143-153, abr./jun.. 1999.

GARCIA JÚNIOR, Armando Álvares. Conflito entre normas do mercosul e direito interno: como resolver o caso brasileiro? São Paulo : LTr, 1997.

HART, Herbert L. A.. O conceito de direito. 2 ed. Lisboa : Calouste Gulbenkian, 1994.

JACKSON, John. H.. Status of treaties in domestic legal systems: a policy analisis. American Journal of International Law. Washington, 1992, v. 86, n. 2, p. $310-340$.

KELSEN, Hans. Teoria geral do estado e do direito. São Paulo : Martins Fontes, 1998a. . Teoria pura do direito. 6 ed. São Paulo : Martins Fontes, 1998b. 
LITRENTO, Oliveiros L. Manual de direito internacional público. Rio de Janeiro : Forense, [1968?].

MELLO, Celso D. de Albuquerque. Direito constitucional internacional. 2 ed. Rio de Janeiro : Renovar, 2000.

O'CONNELL, D. P. International law. London : Stevens \& Sons, 1965. REUTER, Paul. Introdución al derecho de los tratados. México, D. F. : Fondo de Cultura Económica, 1999.

REZEK, J. F. Direito Internacional Público. 7 ed. São Paulo : Saraiva, 1998.

VALLEJO, Manuel Diez de Velasco. Instituciones de derecho internacional público. 12 ed. Madrid : Tecnos, 1999. 